\title{
EVALUATING ASSOCIATION BETWEEN IMPLEMENTATION OF ISO 14031 GUIDELINES AND ISO 14001 CERTIFICATION BY INDUSTRIAL SECTOR IN SAUDI ARABIA
}

\author{
Mohamed MANSOUR $^{1,2^{*}}$, Saleh ALSULAMY ${ }^{1}$ \\ ${ }^{1}$ College of Engineering, King Khalid University, 394 Abha, Saudi Arabia \\ ${ }^{2}$ College of Engineering, Zagazig University, 44519 Zagazig, Egypt
}

Received 03 August 2020; accepted 15 October 2020

\begin{abstract}
Highlights
Positive, negative, and no effect association between ISO 14001 certification and organizations' environmental performance exist in literature.

The association among environmental performance evaluation requirements in ISO 14031:2013 and ISO 14001:2015 certification status for industrial organizations is defined.

The Phi correlation analysis indicated a significant medium positive correlation ranging from 0.358 and 0.537 among the model's variables and the certification status of organizations.
\end{abstract}

\begin{abstract}
Conflicting research results regarding the application of environmental management systems on the environmental performance of industrial organizations between positive, negative, and no effect made studying this relationship a complex research problem. This study aimed to assess the extent of the commitment of industrial organizations in Saudi Arabia in applying ISO 14031:2013 guidelines to evaluate environmental performance and to study the association between the guideline implementation by ISO 14001:2015 certified and uncertified organizations. Using the descriptive approach, the association was identified between 13 independent variables representing ISO 14031:2013 guidelines for environmental performance evaluation and ISO 14001:2015 certification based on a 596 organizations survey conducted from May to December 2020, in addition to comparing the results of the study with similar studies. The results showed a medium positive correlation of ISO 14031 measurement variables with ISO 14001 certification. The study answered the question concerning the association of implementing of ISO 14031 guidelines to evaluate the environmental performance of ISO 14001 certified or uncertified organizations. Limited resources organizations should focus on monitoring environmental indicators and concentrate of planning activities to ensure the organizations uses environmental condition indicators data efficiently. Future studies are necessary to determine causal relationships, to develop specific environmental performance measures, and to integrate ISO 14031 in ISO 14001.
\end{abstract}

Keywords: environmental management systems, ISO 14001, ISO 14031, association, Phi correlation coefficient, TURF analysis.

\section{Introduction}

In recent years, environmental decision-makers are interested in investigating the effect of implementation of Environmental Performance Evaluation (EPE) guidelines given in the international standard ISO 14031:2013 (International Organization for Standardization [ISO], 2013) in industry within ISO 14001:2015 (ISO, 2015) framework Falqi, Alsulamy, and Mansour (2020). This interest due to the relationship between EPE and corporate performance for the industrial organization (Orlitzky et al., 2011). The benefits of Environmental Management System (EMS) certification were categorized into environmental management practices, environmental performance, and awareness (Mihailescu et al., 2011). Waxin, Knuteson, and Bartholomew (2019) added to the benefits from certification that improved business performance. Tarí, Molina-Azorín, and Heras (2012) reviewed the literature on the benefits of ISO 14001 certification.

ISO 14001 was first published on $1^{\text {st }}$ September 1996. The recent 2015 edition emphasis a reinforced approach when compared with 2004 edition on performance

*Corresponding author. E-mail: momansor@kku.edu.sa 
improvement by minimizing the water and energy consumption as well as producing less emission and waste, introducing a life cycle perspective, and developing an external and internal communications strategy (Fonseca, 2015). The concept of certification against ISO 14001:2015 by a recognized certification body should demonstrate that it has competent management and staff and that it is impartial and free from conflicts of interest. While the concept of certification against ISO/IEC 17021-1:2015 standard by a recognized accreditation body, demonstrating capability to fulfill the applicable requirements and generate confidence to its stakeholders (Fonseca et al., 2017). ISO 14001:2015 scope, Section 4.4, and Section 5.2 require an organization to evaluate and enhance EPE (ISO, 2015).

It is important to implement the guidelines given in ISO 14031:2013 EPE for effective organization management through the use of EPE to improve the EP (ISO, 2013). ISO 14031 promote to manage an organization's EP (Ren, 2000). The benefits achieved in implementing EPE is ranked as a) establishing standards for environmental management process, b) providing yardsticks for continuous improvement, c) highlighting environmentally techniques, d) Enhancing communications, e) Benchmarking, f) Tracking the link between efforts and performance, g) Increasing overall business competitiveness, and h) Costeffectiveness in choosing environmental management approaches (Tam et al., 2002). Hopkinson, James, and Sammut (2010) suggested comparing the EP of organization using environmental reports.

Boiral, Guillaumie, Heras-Saizarbitoria, and Tayo Tene (2018) weighted the EPE due to ISO 14001 adoption as waste minimization and management, air pollution, EP in general, energy and resources consumption, environmental risks and safety issues, and water contamination respectively based on 94 published article. The article presented conflicting results about the effect of ISO 14001 certification on EP.

Djekic, Rajkovic, Tomic, Smigic, and Radovanovic (2014) highlighted the lowest ranked benefit of implementing ISO 14001 was waste reduction and emergency responses based on 20 ISO 14001 certified Serbian food companies. Hasan and Chan (2014) indicated a strong evidence for a positive impact of certification on environmental management based on 10510 email responses (response rate $=10.35 \%$ ) of top management participants working in 18 functional areas. Martín-Peña, Díaz-Garrido, and Sánchez-López (2014) carried out a factor analysis based on 228 firms including manufacturers and suppliers from Spanish automotive industry to investigate ISO 14001 latent constructs. Authors concluded a significance improvements in environmental performance. Schylander and Martinuzzi (2007) described the ISO 14001's effects in Austria. Results showed ISO 14001 certification often leads to reduced waste. Curkovic and Sroufe (2011) reported a significant positive effect of certification to achieve a proactive environmental management in automative industry. Conversely, Ghisellini and Thurston (2005) concluded the effectiveness of the ISO 14001 standard are often far from reality for Illinois certified companies. Zobel (2013) showed that certification does not have a significant impact on air emissions, water emissions, resource use, energy use, waste and overall environmental performance in manufacturing firms in Sweden. Also, Zobel (2015) investigated hazardous waste, waste to landfill and the total amounts of waste over 12 years for 66 certified and 50 uncertified Swedish manufacturing organizations Results indicated the certification has no significant impact on waste.

Testa et al. (2014) investigated the difference between ISO 14001 and EMAS implementation of 229 companies in Italy based on the measurement of carbonic anhydride emissions. They suggested a significant effect on air pollution reduction and difference in the effect on ISO 14001 companies compared with EMAS companies. A significant air pollution reduction is approved by Martín-Peña et al. (2014) in Spanish automotive industry. Alemagi, Oben, and Ertel (2006) supported air pollution reduction by EMAS adoption in oil industry along the Atlantic coast of Cameroon. Conversely, some researchers found the relation between ISO 14001 certification and air pollution reduction is not statistically significant based on statistical measures. Aravind and Christmann (2011) argued ISO 14001 certification might not reflect a significant EP of governmental organization and EP does not differ for certified or uncertified organizations supported the conclusion by Ghisellini and Thurston (2005). Also, Gomez and Rodriguez (2011) investigated the toxic release index for 56 certified and 70 uncertified companies. The results indicated ISO 14001 certification does not indicate a positive signal in reducing air pollution. Zobel (2013) showed that certification does not have a significant impact on air emissions in manufacturing firms in Sweden.

With regard to the findings about EP in general, some authors found a positive effect and others found no effect. Zhang, Wang, and Wang (2014) measured and compared74 indicators and sub-indicators of a Shanghai ISO 14001 certified coating firm. Results indicated an improvement in EP in 2008 compared with 2009. Prajogo, Ailie, and Lai (2014) examined the result of adopting ISO 14001 standard on production, procurement, sales, logistics, and $\mathrm{R} \& \mathrm{D}$ functions of 286 companies in Australia. Results indicated a positive effect on green products, processes, and supply chain management. Poksinska (2003) found the Sweden companies prefer to implement ISO 9001 rather than ISO 14001. Results indicated that the significant benefits from ISO 14001 implementation were improved stakeholders' raelations and marketing advantages. Link and Naveh (2006) concluded a positive EP for ISO 14001 certified organizations in terms of better organizational EP and positive employee's discretion. Turk (2009) suppoted a psitive impact of ISO 14001 certification on EP based on a survey for 68 top rated private construction firms. While 5 articles found no significant improvement related to the standard (Boiral \& Henri, 2012; King et al., 2005; Prajogo et al., 2012; Zobel, 2013). 
With regard to energy and resources consumption, Djekic et al. (2014) concluded that the implementation of ISO 14001 leads to savings in water and energy consumptions based on a survey on 20 Serbian food companies. Hasan and Chan (2014) found a reduction in reducing waste and usage of materials and energy based on the opinions of 170 ISO 14001 certified organizations. Aslo, Castka and Prajogo (2013) reported a reduction in pollution and energy consumption. In contrast to these studies, Zeng, Tam, Tam, and Deng (2005) and Zobel (2013) reprted that there is no statistical significant differences between certified and non-certified firms regarding the change in air emissions, water emissions, resource use, energy use, waste and overall environmental performance. ISO 14001 certification lead to a reduction in risk and safety issues as found by Djekic et al. (2014) in certified Serbian food companies, Alemagi et al. (2006) supported a positive effect based on a survey for all compenies along the Atlantic coast of Cameroon, Zeng et al. (2005) concluded that ther is a positive relationship betwoeen certification and reducing risk in selected industries in Chine, and Radonjič and Tominc (2006) reached for the same conclusion in Slovenia's companies.

With respect to the effect of ISO 14001 certification on water contamination, All studies have not found significant improvements (Gomez \& Rodriguez, 2011; Potoski \& Prakash, 2013; Zobel, 2013). Wang and Zhao (2020) analyzed the influence of ISO 14001 certification on firms' financial performance and examined the moderating effect of firm size and age, considering the time factor using the data of 63 firms from the Shenzhen and Shanghai Stock Exchanges in China during 2003-2018. Authors concluded ISO 14001 certification negatively affects the financial performance of firms; also, the negative effects decrease in line with the increase of certification time. Authors concluded firm size and age are positively related to the relationship between ISO 14001 certification and a firm's financial performance. According to Murmura, Liberatore, Bravi, and Casolani (2018), there is an important relation of similarity between ISO 14001 and EMAS and certification's time is a relevant discriminating factor. Fonseca and Domingues (2018) assessed ISO 14001:2015 transition process among Portuguese ISO 14001 certified organizations to get significant benefits of alignment with business strategy, improved top management commitment, and improved internal and external communication. Conversely, Link and Naveh (2006) concluded that implementing ISO 14001 does not have any effect on the business performance.

From our literature review, some studies reported mixed results regarding waste management (Ghisellini \& Thurston, 2005) or no improvement (Zobel, 2013). No reduction in energy and resource consumption was reported by some studies (Zeng et al., 2005; Zobel, 2013). In addition, Gomez and Rodriguez (2011) reported no significant effect of ISO 14001 certification on air pollution. However, Zobel (2013) and Gomez and Rodriguez (2011) found a significant effect on water pollution. There is no agreement between researchers about the association between the application of an EMS such as ISO 14001 and the EP of an organization. While some researchers view a positive relationship; the ISO 14001 certification increases the EP, others see a negative relationship; ISO 14001 certification reduced EP. Others argue that there is no association between the ISO 14001 certification and EPE's level. The conflicting research results in the literature regarding the association between implementing ISO 14001:2015 and EPE makes this research area an attractive one (Mansour et al., 2019). This study explored the association between EPE and ISO 14001 certification. The study used ISO 14031:2013 guidelines to evaluate EP. Moreover, it is clear that there is no study evaluated the impact of implementing ISO 14031 guidelines on institutions' EP, which would rank the importance of these guidelines according to the extent of their relevance to the EP's development. The ranking allows organizations and government to focus their limited resources to achieve the highest level of EP by using the least amount of resources.

The purpose of this quantitative study is to examine ISO 14001:2015 certification and implementing ISO 14031:2013 EPE's guidelines by industrial organizations in Saudi Arabia in 2020. The importance of studying the relationship is that the implementation of the guidelines is not compulsory to obtain the certificate, and therefore the organization may grant for ISO 14001 certification without implementing ISO 14031. For this reason, this study came to clarify ISO 14001-ISO 14031 relationship. In the case of a proven relationship, we can call for combining ISO 14031 with ISO 14001, and if the relationship is not proven, then we can call for canceling the guidelines given in ISO 14031.

In summary, this study aimed to measure the association between implementing ISO 14031:2013 guidelines for EPE and the ISO 14001 certification status of industrial organizations. This led to the following research question: Do the ISO 14031 guidelines for EPE significantly correlate with ISO 14001 certification? The null hypothesis $(\mathrm{HO})$ was that there is an association between implementing the EPE guidelines given in ISO 14031 and ISO 14001 certification, against the alternative hypothesis $(H 1)$ that there is no association. Besides determining the best combinations for ISO 14031's guidelines, which limited resources organizations can focus on matching their environmental system to ISO 14001 requirements, which governments can focus on when developing EPE's procedures and monitoring systems of industrial organizations whether they have or have-not ISO 14001 certification. This study can be the first step to discovering the association between ISO 14001:2015 certification and implementing the EPE guidelines given in ISO 14031:2013. Total Unduplicated Reach and Frequency (TURF) analysis is used to determine the best ISO 14031's guidelines combinations. The remainder of this article covers the following. The first section focuses on solution methodology. In the second 
section, results and discussion apply the solution methodology to evaluate the association between ISO 14031 guideline implementation and ISO 14001 certification based on the opinion and judgment of industrial experts. The last section gives conclusions combines the findings after considering all association coefficients in the study.

\section{Materials and methods}

A questionnaire consisting of 14 questions was designed to be answered by "yes" or "no". The first question was about whether or not the organization was ISO 14001 certified. The remaining 13 questions represented the state of the organization in terms of the application of key ISO 14031 data for environmental performance assessment as shown in Table 1. A response rate of $30 \%$ is a considered acceptable (Sekaran \& Bougie, 2013). The questionnaire included three dimensions, namely EPE's planning, the use of data and information, and EPE's reviewing and improving, consisting of five, six, and two measurement variables, respectively. The "EPE's planning" variables are represented by the symbols P1 to P5. The "use of data and information" variables are denoted by the symbols D1 to D6. Finally, the "reviewing and improving EPE" variables are denoted by R1 and I1. The questionnaire was distributed to 900 organizations involved in 30 economic activities in Saudi Arabia by email from January to March 2020. The organizations to which emails were sent included 317 certified and 583 uncertified organizations. 282 of 317 organizations renewed their ISO 14001 certification and transitioned to the 2015 edition. Table 2 shows a sample structure to show the sample size in each economic activity and the statuses of organizations from the ISO 14001 certification.

For example, the questionnaire was sent to $n 1=46$ organizations in the construction sector, representing $19.59 \%$ of the total number of questionnaires sent to organizations holding ISO 14001 certificates. In addition, the questionnaire was sent to $n 2=60$ organizations in the construction sector, representing $16.62 \%$ of the number of uncertified organizations. Consequently, the total number of organizations to which the questionnaire was sent was $n t=106$, operating in the construction sector, which represented $17.79 \%$ of the total of 900 organizations. The completed questionnaires were returned, collected, and prepared for processing using the RapidMiner software (Ingo \& Klinkenberg, 2019). The data were cleaned by removing high-quality, duplicate, incomplete, and highly linked records (Kotu \& Deshpande, 2015). The data were described using a descriptive statistical method. To validate the data, a feedback call was made to a group of 150 organizations to ensure the accuracy of the data collected. In total, 596 of the 900 questionnaires collected were completed fully and were, therefore, appropriate for the statistical analysis. The group included 235 certified organizations and 361 uncertified organizations involved in 30 economic activities. The Phi correlation coefficient was used at a level of significance of $\alpha=0.05$ to test the study hypothesis.
Table 1. Questionnaire items on the implementation of the ISO 14031 standard

\begin{tabular}{|c|c|c|c|c|}
\hline Stage & Code & Definition & $\begin{array}{l}\mathrm{Ag}- \\
\text { ree }\end{array}$ & $\begin{array}{l}\text { Dis- } \\
\text { agree }\end{array}$ \\
\hline \multirow{5}{*}{$\begin{array}{l}\text { Planning } \\
\text { for EPE }\end{array}$} & $\mathrm{P} 1$ & $\begin{array}{l}\text { EPE planning is based on } \\
\text { the significant/controlling } \\
\text { environmental aspects }\end{array}$ & & \\
\hline & P2 & $\begin{array}{l}\text { EPE planning is based on EP } \\
\text { criteria and on the views of } \\
\text { interested parties }\end{array}$ & & \\
\hline & P3 & $\begin{array}{l}\text { The organization selects } \\
\text { and uses management } \\
\text { performance indicator data } \\
\text { efficiently }\end{array}$ & & \\
\hline & $\mathrm{P} 4$ & $\begin{array}{l}\text { The organization selects and } \\
\text { uses operational performance } \\
\text { indicator data efficiently }\end{array}$ & & \\
\hline & P5 & $\begin{array}{l}\text { The organization selects and } \\
\text { uses environmental condition } \\
\text { indicator data efficiently }\end{array}$ & & \\
\hline \multirow{6}{*}{$\begin{array}{l}\text { Use of } \\
\text { data and } \\
\text { infor- } \\
\text { mation }\end{array}$} & D1 & $\begin{array}{l}\text { The use of data and } \\
\text { information to evaluate EP } \\
\text { is based on documented } \\
\text { procedures }\end{array}$ & & \\
\hline & $\mathrm{D} 2$ & $\begin{array}{l}\text { The organization collects data } \\
\text { regularly and systematically } \\
\text { from sources, consistent with } \\
\text { EPE planning }\end{array}$ & & \\
\hline & D3 & $\begin{array}{l}\text { The organization analyses } \\
\text { and converts the collected } \\
\text { data into information } \\
\text { describing the organization's } \\
\text { environmental performance }\end{array}$ & & \\
\hline & D4 & $\begin{array}{l}\text { The EPE's analyzed data } \\
\text { compared with the orga- } \\
\text { nization's EP criteria indicate } \\
\text { progress or deficiencies in } \\
\text { environmental performance }\end{array}$ & & \\
\hline & D5 & $\begin{array}{l}\text { Management ensure that } \\
\text { appropriate and necessary } \\
\text { information describing the } \\
\text { organization's EP is com- } \\
\text { municated throughout the } \\
\text { organization timeously }\end{array}$ & & \\
\hline & D6 & $\begin{array}{l}\text { The organization may choose } \\
\text { or may be required to issue } \\
\text { environmental reports } \\
\text { or statements providing } \\
\text { information describing its EP } \\
\text { to external interested parties }\end{array}$ & & \\
\hline \multirow{2}{*}{$\begin{array}{l}\text { Revie- } \\
\text { wing and } \\
\text { impro- } \\
\text { ving EPE }\end{array}$} & $\mathrm{R} 1$ & $\begin{array}{l}\text { The organization's EPE } \\
\text { and its results should be } \\
\text { reviewed periodically to } \\
\text { identify opportunities for } \\
\text { improvement }\end{array}$ & & \\
\hline & I1 & $\begin{array}{l}\text { The review contributes to } \\
\text { management actions to } \\
\text { improve the management } \\
\text { and operation of the } \\
\text { organization, which results } \\
\text { in the improvement of the } \\
\text { organizational environment }\end{array}$ & & \\
\hline
\end{tabular}


The data were entered and analyzed using SPSS software (IBM, 2017) on Windows 10 and analyzed. TURF analysis module in SPSS is used to rank combinations of ISO 14031's variables by how many respondents implemented these combinations (Adler et al., 2010). TURF module is adjusted to maximum variable combinations is 4 , number of combinations to display is 13 , and positive response value is 1 .

\section{Results and discussion}

The sample consists of 596 organizations, including 235 certified organizations and 361 uncertified organizations representing a considerable accepted response rate of $66.22 \%$ that represents an acceptable response rate (Sekaran \& Bougie, 2013). Organizations profile with regard to year of certification are $1 \%$ certified before 2006, 55\% certified between 2006 and 2007, 40\% of organizations are certified between in the period of 2008-2009, and the remaining percentage is certified after 2009. Most (66.22\%) of the organizations' managers answered the questionnaire fully, while $22.78 \%$ of the questionnaires were excluded after a data cleaning process. 140 organizations are excluded due to nonresponse bias including 51 surveys did not reach participant due to emails problems, 35 organizations refuse to respond, and 55 organizations were unable to perform tasks associated with answering due to the unavailability of the mangers or their representatives. 45 organizations out of 150 ones were omitted from the study after a feedback call to check the response bias. 118 organization were omitted from the study due to missing data problems. The responses covered 30 industrial fields such as agriculture, fishing, and forestry, then basic metal and fabricated metal products, and so on as shown given in Table 2. For example, 46 organizations representing 19.57\% of the 235 certified organizations in the construction sector answered the questionnaires fully. 596 respondents include 298 organization mangers, 238 environmental department managers, and 60 safety manger with average years of experience of $10,12.5$, and 6.5 years with standard deviations of $1.25,1.15,0.98$ years standard deviations respectively.

Frequencies for the environmental performance evaluation independent variable are shown in Table 3. As the table shows, $77.00 \%$ of the certified organizations answered that they implemented P1, representing 66.30\% of the 273 organizations implementing this variable. In terms of $\mathrm{P} 2,69.40 \%$ of certified organizations answered that they implemented the variable, representing 63.70\% of the 256 organizations implementing it. The variable P3 was implemented by $68.90 \%$ of the certified organizations, representing $56 \%$ of the 259 organizations implementing this variable. In terms of $\mathrm{P} 4,63.80 \%$ of the certified organizations answered that they implemented it, representing $60.00 \%$ of the 250 organizations implementing this variable. Finally, $77.90 \%$ of the certified organizations answered
Table 2. Response rates of certified and uncertified organizations and their industrial fields

\begin{tabular}{|c|c|c|c|c|c|c|c|}
\hline \multirow[t]{2}{*}{$\begin{array}{l}\text { Sr. } \\
\text { No. }\end{array}$} & \multirow[t]{2}{*}{ Industrial Sector } & \multicolumn{2}{|c|}{$\begin{array}{c}\text { \# of } \\
\text { certified } \\
\text { org. }\end{array}$} & \multicolumn{2}{|c|}{$\begin{array}{l}\text { \# of un- } \\
\text { certified } \\
\quad \text { org. }\end{array}$} & \multicolumn{2}{|c|}{ Total } \\
\hline & & $n_{1}$ & $\%$ & $n_{2}$ & $\%$ & $n_{t}$ & $\%$ \\
\hline 1 & $\begin{array}{l}\text { Agriculture, fishing, and } \\
\text { forestry }\end{array}$ & 1 & 0.4 & 3 & 0.8 & 4 & 0.7 \\
\hline 2 & $\begin{array}{l}\text { Basic metal and fabricated } \\
\text { metal products }\end{array}$ & 20 & 8.5 & 30 & 8.3 & 50 & 8.4 \\
\hline 3 & $\begin{array}{l}\text { Chemicals, chemical } \\
\text { products, and fibers }\end{array}$ & 11 & 4.7 & 20 & 5.5 & 31 & 5.2 \\
\hline 4 & $\begin{array}{l}\text { Concrete, cement, lime, } \\
\text { plaster, etc. }\end{array}$ & 6 & 2.6 & 10 & ${ }^{2} .8$ & 16 & 2.7 \\
\hline 5 & Construction & 46 & 19.6 & 60 & 16.6 & 106 & 17.8 \\
\hline 6 & Education & 2 & 0.9 & 8 & 2.2 & 10 & 1.7 \\
\hline 7 & $\begin{array}{l}\text { Electrical and optical } \\
\text { equipment }\end{array}$ & 7 & 3.0 & 8 & 2.2 & 15 & 2.5 \\
\hline 8 & Electricity supply & 2 & 0.9 & 4 & 1.1 & 6 & 1.0 \\
\hline 9 & Engineering services & 25 & 10.6 & 35 & 9.7 & 60 & 10.1 \\
\hline 10 & $\begin{array}{l}\text { Financial intermediation, } \\
\text { real estate, and renting }\end{array}$ & 5 & 2.1 & 10 & 2.8 & 15 & 2.5 \\
\hline 11 & $\begin{array}{l}\text { Food products, beverage, } \\
\text { and tobacco }\end{array}$ & 13 & 5.5 & 18 & 5.0 & 31 & 5.2 \\
\hline 12 & Health and social work & 1 & 0.4 & 5 & 1.4 & 6 & 1.0 \\
\hline 13 & Hotels and restaurants & 1 & 0.4 & 3 & 0.8 & 4 & 0.7 \\
\hline 14 & Information technology & 2 & 0.9 & 5 & 1.4 & 7 & 1.2 \\
\hline 15 & Machinery and equipment & 9 & 3.8 & 15 & 4.2 & 24 & 4.0 \\
\hline 16 & $\begin{array}{l}\text { Manufacture of coke and } \\
\text { refined petroleum products }\end{array}$ & 7 & 3.0 & 8 & 2.2 & 15 & 2.5 \\
\hline 17 & $\begin{array}{l}\text { Manufacture of wood and } \\
\text { wood products }\end{array}$ & 1 & 0.4 & 5 & 1.4 & 6 & 1.0 \\
\hline 18 & $\begin{array}{l}\text { Non-metallic mineral } \\
\text { products }\end{array}$ & 2 & 0.9 & 3 & 0.8 & 5 & 0.8 \\
\hline 19 & Other services & 2 & 0.9 & 4 & 1.1 & 6 & 1.0 \\
\hline 20 & Other social services & 1 & 0.4 & 5 & 1.4 & 6 & 1.0 \\
\hline 21 & Pharmaceuticals & 1 & 0.4 & 3 & 0.8 & 4 & 0.7 \\
\hline 22 & Printing companies & 1 & 0.4 & 5 & 1.4 & 6 & 1.0 \\
\hline 23 & Public administration & 9 & 3.8 & 15 & 4.2 & 24 & 4.0 \\
\hline 24 & $\begin{array}{l}\text { Pulp, paper, and paper } \\
\text { products }\end{array}$ & 1 & 0.4 & 5 & 1.4 & 6 & 1.0 \\
\hline 25 & Recycling & 15 & 6.4 & 20 & 5.5 & 35 & 5.9 \\
\hline 26 & $\begin{array}{l}\text { Rubber and plastic } \\
\text { products }\end{array}$ & 4 & 1.7 & 8 & 2.2 & 12 & 2.0 \\
\hline 27 & $\begin{array}{l}\text { Textiles and textile } \\
\text { products }\end{array}$ & 6 & 2.6 & 10 & 2.8 & 16 & 2.7 \\
\hline 28 & $\begin{array}{l}\text { Transport, storage, and } \\
\text { communication }\end{array}$ & 5 & 2.1 & 8 & 2.2 & 13 & 2.2 \\
\hline 29 & Water supply & 17 & 7.2 & 17 & 4.7 & 34 & 5.7 \\
\hline 30 & $\begin{array}{l}\text { Wholesale and retail trade, } \\
\text { repairs of motor vehicles, } \\
\text { motorcycles, and personal } \\
\text { and household goods }\end{array}$ & 2 & 0.9 & 4 & 1.1 & 6 & 1.0 \\
\hline & Total & 235 & 100 & 361 & 100 & 596 & 100 \\
\hline
\end{tabular}


that they implemented P5, representing $68.50 \%$ of the 267 organizations implementing this variable.

In terms of the use of data and information, $68.90 \%$ of the certified organizations answered that they implemented D1, representing $62.80 \%$ of the 258 organizations implementing this variable. Regarding the D2 variable, $73.60 \%$ of the certified organizations answered that they implemented it, representing $64.60 \%$ of the 268 organizations implementing this variable. The variable D3 was implemented by $74.50 \%$ of the certified organizations, representing $62.90 \%$ of the 278 organizations implementing this variable. The variable D4 was implemented by $66.80 \%$ of the certified organizations, representing $62.30 \%$ of the 252 organizations implementing this variable. With regard to D5, 69.40\% of certified organizations answered that they implemented the variable, representing $60.60 \%$ of the 269 organizations implementing it. Finally, $72.80 \%$ of the certified organizations answered that they implemented D6, representing 64.50\% of the 265 organizations implementing this variable. With regard to $\mathrm{R} 1,67.20 \%$ of the certified organizations answered that they implemented the variable, representing $63.20 \%$ of the 250 organizations implementing it. In addition, $74.00 \%$ of the certified organizations answered that they implemented I1, representing $64.20 \%$ of the 271 organizations implementing this variable.

Table 4 presents the Phi coefficient values, which were $0.505,0.430,0.415,0.358$, and 0.537 for P1, P2, P3, P4, and $\mathrm{P} 5$, respectively, in association with the organizational status variable $Y$. This suggests that there is a positive association between the variables. However, the $p$-value $\approx$ .000 in the table suggests a highly statistically significant association. The Phi coefficient values of $0.418,0.465$, $0.450,0.401,0.393$, and 0.460 for D1, D2, D3, D4, D5, and D6, respectively, represent the association between the "D" variables and $Y$. These values indicate a positive association between the variables in addition to the $p$-value $\approx .000$ in the table, suggesting a highly statistically significant association. The Phi coefficient between R1 and $\mathrm{Y}$ was 0.413 , whereas its value was 0.463 between I1 and $\mathrm{Y}$, indicating a medium positive association between the variables. The $p$-value $\approx .000$ in the table suggests a highly statistically significant association.

Table 3. Frequency table for the environmental performance evaluation independent variable

\begin{tabular}{|c|c|c|c|c|c|c|c|}
\hline \multirow{3}{*}{$\begin{array}{l}\text { ISO } 14031 \\
\text { variable }\end{array}$} & \multirow{3}{*}{ Value } & \multicolumn{6}{|c|}{ ISO 14001 Status } \\
\hline & & \multicolumn{3}{|c|}{$Y=0$} & \multicolumn{3}{|c|}{$Y=1$} \\
\hline & & Count & Row $N \%$ & Column $N \%$ & Count & Row $N \%$ & Column $N \%$ \\
\hline \multirow{2}{*}{$\mathrm{P} 1$} & 0 & 269 & 83.30 & 74.50 & 54 & 16.70 & 23.00 \\
\hline & 1 & 92 & 33.70 & 25.50 & 181 & 66.30 & 77.00 \\
\hline \multirow{2}{*}{$\mathrm{P} 2$} & 0 & 268 & 78.80 & 74.20 & 72 & 21.20 & 30.60 \\
\hline & 1 & 93 & 36.30 & 25.80 & 163 & 63.70 & 69.40 \\
\hline \multirow{2}{*}{$\mathrm{P} 3$} & 0 & 264 & 78.30 & 73.10 & 73 & 21.70 & 31.10 \\
\hline & 1 & 97 & 37.50 & 26.90 & 162 & 62.50 & 68.90 \\
\hline \multirow{2}{*}{$\mathrm{P} 4$} & 0 & 261 & 75.40 & 72.30 & 85 & 24.60 & 36.20 \\
\hline & 1 & 100 & 40.00 & 27.70 & 150 & 60.00 & 63.80 \\
\hline \multirow{2}{*}{ P5 } & 0 & 277 & 84.20 & 76.70 & 52 & 15.80 & 22.10 \\
\hline & 1 & 84 & 31.50 & 23.30 & 183 & 68.50 & 77.90 \\
\hline \multirow{2}{*}{ D1 } & 0 & 265 & 78.40 & 73.40 & 73 & 21.60 & 31.10 \\
\hline & 1 & 96 & 37.20 & 26.60 & 162 & 62.80 & 68.90 \\
\hline \multirow{2}{*}{ D2 } & 0 & 266 & 81.10 & 73.70 & 62 & 18.90 & 26.40 \\
\hline & 1 & 95 & 35.40 & 26.30 & 173 & 64.60 & 73.60 \\
\hline \multirow{2}{*}{ D3 } & 0 & 258 & 81.10 & 71.50 & 60 & 18.90 & 25.50 \\
\hline & 1 & 103 & 37.10 & 28.50 & 175 & 62.90 & 74.50 \\
\hline \multirow{2}{*}{ D4 } & 0 & 266 & 77.30 & 73.70 & 78 & 22.70 & 33.20 \\
\hline & 1 & 95 & 37.70 & 26.30 & 157 & 62.30 & 66.80 \\
\hline \multirow{2}{*}{ D5 } & 0 & 255 & 78.00 & 70.60 & 72 & 22.00 & 30.60 \\
\hline & 1 & 106 & 39.40 & 29.40 & 163 & 60.60 & 69.40 \\
\hline \multirow{2}{*}{ D6 } & 0 & 267 & 80.70 & 74.00 & 64 & 19.30 & 27.20 \\
\hline & 1 & 94 & 35.50 & 26.00 & 171 & 64.50 & 72.80 \\
\hline \multirow{2}{*}{$\mathrm{R} 1$} & 0 & 269 & 77.70 & 74.50 & 77 & 22.30 & 32.80 \\
\hline & 1 & 92 & 36.80 & 25.50 & 158 & 63.20 & 67.20 \\
\hline \multirow{2}{*}{ I1 } & 0 & 264 & 81.20 & 73.10 & 61 & 18.80 & 26.00 \\
\hline & 1 & 97 & 35.80 & 26.90 & 174 & 64.20 & 74.00 \\
\hline
\end{tabular}


Table 4. Phi correlation coefficients between ISO 14001 certification status and ISO 14031 guidelines

\begin{tabular}{|c|c|c|}
\hline $\begin{array}{c}\text { ISO 14031 } \\
\text { measurement } \\
\text { variables }\end{array}$ & $\begin{array}{c}\text { Phi correlation } \\
\text { coefficient }\end{array}$ & $p$-value \\
\hline P1 & $0.505^{*}$ & 0.000 \\
\hline P2 & $0.430^{*}$ & 0.000 \\
\hline P3 & $0.415^{*}$ & 0.000 \\
\hline P4 & $0.358^{*}$ & 0.000 \\
\hline P5 & $0.537^{*}$ & 0.000 \\
\hline D1 & $0.418^{*}$ & 0.000 \\
\hline D2 & $0.465^{*}$ & 0.000 \\
\hline D3 & $0.450^{*}$ & 0.000 \\
\hline D4 & $0.401^{*}$ & 0.000 \\
\hline D5 & $0.393^{*}$ & 0.000 \\
\hline D6 & $0.460^{*}$ & 0.000 \\
\hline R1 & $0.413^{*}$ & 0.000 \\
\hline I1 & $0.463^{*}$ & 0.000 \\
\hline
\end{tabular}

Note: ${ }^{*}$ Indicate significance at $p<0.05$.

In conclusion, $71.40 \%$ of the ISO 14001 certified organizations answered that they implemented EPE's planning activities (defined in Table 1 as "P" variables), $71.00 \%$ of the certified organizations answered that they implemented the use of data and information (defined in Table 1 as "D" variables), and $70.60 \%$ of the certified organizations answered that they implemented reviewing and improving EPE activities (defined in Table 1 as "R1" and "I1" variables). The average Phi correlation coefficient for the "P" variables was 0.449 , indicating a medium positive association between the variables with ISO 14001 certification status variable $(\mathrm{Y})$. The Phi value for $\mathrm{P} 4$ was 0.358 , indicating a week positive association between "P" variables and $\mathrm{Y}$, in contrast to $\mathrm{P} 1, \mathrm{P} 2, \mathrm{P} 3$, and $\mathrm{P}$, which indicated a medium positive association with $\mathrm{Y}$. The average Phi correlation coefficient for the " $\mathrm{D}$ " variables was 0.431 , indicating a medium positive association between the variables and $\mathrm{Y}$. The $0.393 \mathrm{Phi}$ value for D5 indicates a week positive association between $\mathrm{D} 5$ and $\mathrm{Y}$, in contrast to D1, D2, D3, D4, and D6, which indicated a medium positive association with $\mathrm{Y}$.

The average Phi correlation coefficient between the reviewing and improving EPE variables (R1 and I1) was 0.438 , indicating a medium positive association between $\mathrm{R} 1$ and I1 with Y. The result excluded from the above findings is that there was a significant medium correlation between implementing ISO 14001:2013 guidelines for EPE and ISO 14001:2015 certification based on the sampled population at $\alpha=0.05$, using the Phi correlation coefficient. This study's findings support the association between EPE and ISO 14001:2015 certifications and concur with some studies (Boiral et al., 2018; Martín-Peña et al., 2014; Nguyen \& Hens, 2015; Zeng et al., 2005) and not in agreement with other studies (Ghisellini \& Thurston, 2005; Gomez \& Rodriguez, 2011; Zobel, 2013).
Table 5 shows the collected data statistics in terms of reach, percentage of cases (Pct of cases), and percentage of responses (Pct of responses). Table shows the number of organizations responded by "Yes" for each ISO 14031's variable. The D3 "The organization analyses and converts the collected data into information describing the organization's environmental performance" achieved the maximum reach among other variable of 278 representing a percentage of 46.6 of total 596 respondents and a percentage of 8.1 responses. D3 variable is followed by P1 "EPE planning is based on the significant/controlling environmental aspects", the number of institutions that answered "Yes" in the survey. P1 achieved a reach of 278, a percentages of cases responded by "Yes" of 46.6, and a percentage of responses equals to 8.0. I1 "The review contributes to management actions to improve the management and operation of the organization, which results in the improvement of the organizational environment" comes in the third rank with a reach of 271 respondents, $46.6 \%$ of cases, and a percentage of responses equals to 7.9. D5 representing "Management ensure that appropriate and necessary information describing the organization's EP is communicated throughout the organization timeously" comes in the fourth rank with a reach of 269 , a percentage of cases equals to 45.1 , and a percentage of responses equals to 7.9. D2, P5, and D6 percentages of responses equals to 7.8 , corresponding to select and use environmental condition indicators, planning EPE based on systematic data collection procedures, and issue environmental reports providing EP's information to external parties. P3 “The organization selects and uses management performance indicator data efficiently" and D1 "The use of data and information to evaluate EP is based on documented procedures" achieved a percentages of responses equals to 7.6 as shown in Table 5. P2 "EPE planning is based on EP criteria and on the views of interested parties" achieved a percentage of responses equals to 7.5, while D4 “The EPE's

Table 5. Maximum group size of 1 (reach and frequency)

\begin{tabular}{|c|c|c|c|}
\hline \multirow{2}{*}{ Variables } & \multicolumn{3}{|c|}{ Statistics } \\
\cline { 2 - 4 } & Reach & Pct of cases & Pct of responses \\
\hline D3 & 278 & 46.6 & 8.1 \\
\hline P1 & 273 & 45.8 & 8.0 \\
\hline I1 & 271 & 45.5 & 7.9 \\
\hline D5 & 269 & 45.1 & 7.9 \\
\hline D2 & 268 & 45.0 & 7.8 \\
\hline P5 & 267 & 44.8 & 7.8 \\
\hline D6 & 265 & 44.5 & 7.8 \\
\hline P3 & 259 & 43.5 & 7.6 \\
\hline D1 & 258 & 43.3 & 7.6 \\
\hline P2 & 256 & 43.0 & 7.5 \\
\hline D4 & 252 & 42.3 & 7.4 \\
\hline R1 & 250 & 41.9 & 7.3 \\
\hline P4 & 250 & 41.9 & 7.3 \\
\hline
\end{tabular}




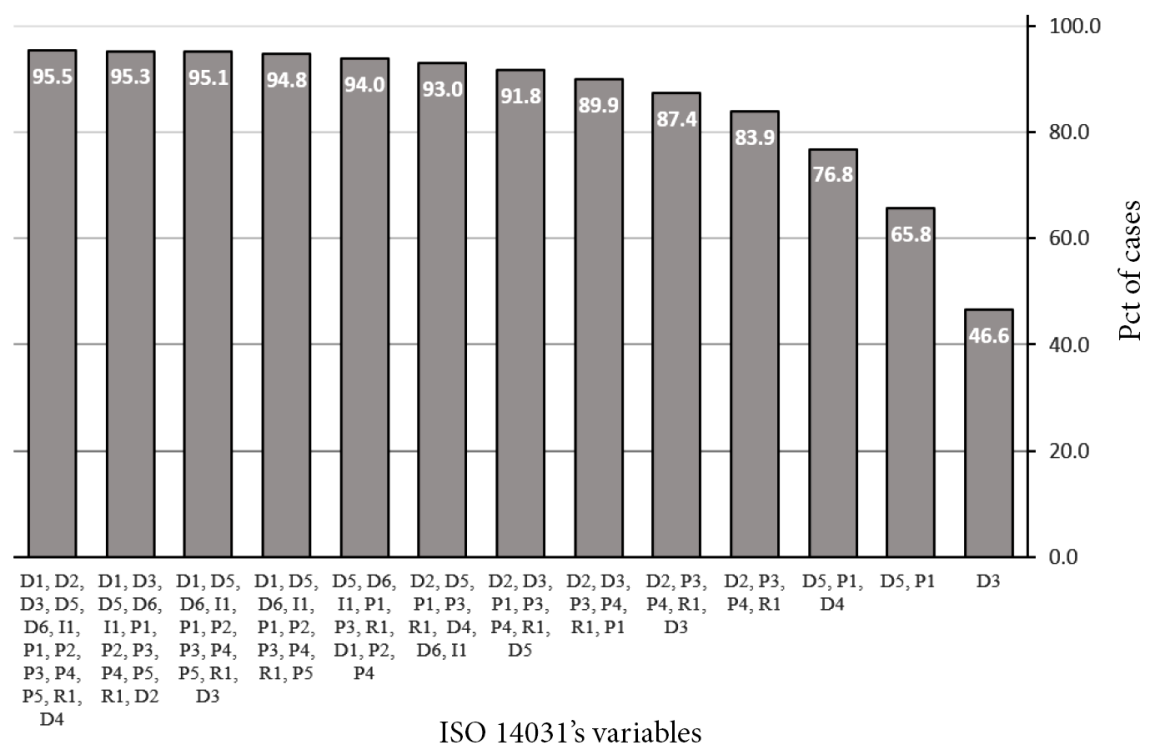

Figure 1. Best reach and frequency by group size

analyzed data compared with the organization's EP criteria indicate progress or deficiencies in environmental performance" achieved a percentage of 7.4. Finally, both R1 and P4 achieved a percentage of responses equals to 7.3.

Figure 1 demonstrates the results of implementing TURF analysis module available in SPSS. Results shows the percentage of respondents answered by "Yes" for ISO 14031 's variable combinations. For example, the most implemented clause in ISO 14031 is D3 "The organization analyses and converts the collected data into information describing the organization's environmental performance" with a percentage of respondents equals to 46.6 as indicated in Table 5. D5 and P1 is the best combinations implemented by organizations with a total percentage of 65.8. The best possible combinations of three implemented clauses are D5, P1, and D4 with a percentage of respondents equals to 76.8 . The best combinations of 4 variables is $\mathrm{D} 2, \mathrm{P} 3, \mathrm{P} 4$, and $\mathrm{R} 1$ with a percentage of 83.9 . The best 5 combinations of variables is D2, P3, P4, R1, and D3 with a percentage of 87.4 as shown in Figure 1.

In conclusion, the most number of respondent certified organizations was working in construction and engineering service which reflect the importance of compliance with environmental regulations and systems by these organizations. Moreover, results indicated that highly statistically significant association between implementing ISO 14031 guidelines and ISO 14001 certification especially planning efforts and activities represented by $\mathrm{P} 1$ "EPE planning is based on the significant/controlling environmental aspects" and P5 "The organization selects and uses environmental condition indicator data efficiently". In the case of limited resources, the organizations can concentrate on implementing D3 guidelines "The organization analyses and converts the collected data into information describing the organization's environmental performance". Implementing D5 "Management ensure that appropriate and necessary information describing the organization's EP is communicated throughout the organization timeously" and P1 "EPE planning is based on the significant/controlling environmental aspects" is the best combination consisting of 2 ISO 14031 guidelines. The best combination consisting of 3 ISO 14031guidlines is D5, P1 and D4 “The EPE's analyzed data compared with the organization's EP criteria indicate progress or deficiencies in environmental performance".

\section{Conclusions}

This article aimed to assess the association between implementing ISO 14031:2013 guidelines for EPE and ISO 14001:2015 certification in the industrial sector using a designed questionnaire survey. The overall conclusion emerging from this study is that there is a significant association between implementing ISO 14031 guidelines for EPE and ISO 14001:2015 certification. The Phi correlation analysis indicated a significant medium positive correlation ranging from 0.358 and 0.537 among the model's variables and the certification status of organizations. Based on the result from TURF analysis, certified and noncertified organizations should concentrate their efforts on collecting the environmental data in a systematic manner and use it in an efficient way to the benefits of the organization and society. The results of the study can be used to construct a statistical model for checking, reviewing, monitoring, and evaluating organizations' environmental performance.

This study will benefit industrial organizations in general and society at large. Organizations will benefit by increasing their understanding of the effect of implementing the guidelines given in the ISO 14031 standard on the ISO 14001 certification. In addition, organizations can use that information as a marketing and development tool. An issue that could have limited the statistical analysis of 
the study was the data's binary nature, which limited the statistical analysis. These could be treated as extensions. Consequently, further research is required to examine the structure of the ISO 14031:2013 model for EPE. Based on our findings, we contribute to the development of the first statistical analysis approving the association between ISO 14001:2015 certification and ISO 14031:2013 guideline implementation in the industrial sector.

For generalizing the results of this study, a comprehensive data collection regarding other countries is required. Although, this study definitely answers the question regarding the association level between implementing the optional guidelines in ISO 14031:2013 and ISO 14001:2015. Further studies are needed to establish casual relationships and develop statistical measures. Moreover, this study limited to evaluating the managerial efforts in the two standards and neglected the value of technical environmental performance indicators. A structure equation model combining the managerial/procedural efforts and environmental performance indicators values is required in further research. The study neglects the year of the first ISO 14001 certification for the respondent companies, hence a future work is required to check for differences between early and late adopters.

Due to the difficulty of comparing the environmental performance of organizations operating in the same economic activity and the impossibility of comparing organizations operating in different activities, the current study is important in presenting the managerial efforts to preserve the environment as a criterion for comparing the environmental performances of organizations. A natural extension for the current study could be to use the principal component analysis technique to explore the validity of the ISO 14031:2015 model to gauge environmental performance in addition to using the explanatory and confirmatory factor analysis. Important implications can be derived from the findings of this study. A construction organization can adopt the developed ISO 14031 model as a useful tool to measure environmental performance, even though it does not implement ISO 14000. More research work is required to investigate the influence of ISO 14001:2015 edition that could yield somewhat different results compared with other works based on previous ISO 14001 editions.

\section{Author contributions}

Conceptualization, methodology, software, validation, formal analysis, investigation, resources, and data curation, M.M.; writing - original draft preparation, writing-review and editing, visualization, supervision, project administration S.A.; The authors have read and agreed to the published version of the manuscript.

\section{Acknowledgements}

We would like to thank the anonymous reviewers for their careful reading of our manuscript and their many insightful comments and suggestions. Also, thanks are due to the deanship of scientific affairs of King Khalid University, Saudi ministry of education (Asser, Kingdom of Saudi Arabia) for assistance with the communication with the industrial organization in the data collection processes. This work was financially supported by the general research program Funds for the King Khalid University [grant number R.G.P. 1/220/41]. The content is solely the responsibility of the authors and does not necessarily represent the official views of the King Khalid University.

\section{Conflict of interest}

The authors declare no conflict of interest.

\section{References}

Adler, T., Smith, C., \& Dumont, J. (2010). Optimizing product portfolios using discrete choice modeling and TURF. In S. Hess \& A. Daly (Eds.), Choice modelling: The State-of-theart and The State-of-practice (pp. 483-497). Emerald Group Publishing Limited.

https://doi.org/10.1108/9781849507738-022

Alemagi, D., Oben, P. M., \& Ertel, J. (2006). Implementing environmental management systems in industries along the Atlantic coast of Cameroon: Drivers, benefits and barriers. Corporate Social Responsibility and Environmental Management, 13(4), 221-232. https://doi.org/10.1002/csr.106

Aravind, D., \& Christmann, P. (2011). Decoupling of standard implementation from certification: does quality of ISO 14001 implementation affect facilities' environmental performance? Business Ethics Quarterly, 21(1), 73-102. https://doi.org/10.5840/beq20112114

Boiral, O., Guillaumie, L., Heras-Saizarbitoria, I., \& Tayo Tene, C. V. (2018). Adoption and outcomes of ISO 14001: A systematic review. International Journal of Management Reviews, 20(2), 411-432. https://doi.org/10.1111/ijmr.12139

Boiral, O., \& Henri, J.-F. (2012). Modelling the impact of ISO 14001 on environmental performance: A comparative approach. Journal of Environmental Management, 99, 84-97. https://doi.org/10.1016/j.jenvman.2012.01.007

Castka, P., \& Prajogo, D. (2013). The effect of pressure from secondary stakeholders on the internalization of ISO 14001. Journal of Cleaner Production, 47, 245-252. https://doi.org/10.1016/j.jclepro.2012.12.034

Curkovic, S., \& Sroufe, R. (2011). Using ISO 14001 to promote a sustainable supply chain strategy. Business Strategy and the Environment, 20(2), 71-93. https://doi.org/10.1002/bse.671

Djekic, I., Rajkovic, A., Tomic, N., Smigic, N., \& Radovanovic, R. (2014). Environmental management effects in certified Serbian food companies. Journal of Cleaner Production, 76, 196199. https://doi.org/10.1016/j.jclepro.2014.04.062

Falqi, I., Alsulamy, S., \& Mansour, M. (2020). Environmental performance evaluation and analysis using ISO 14031 guidelines in construction sector industries. Sustainability, 12(5), 1774. https://doi.org/10.3390/su12051774

Fonseca, L. (2015). ISO 14001: 2015: An improved tool for sustainability. Journal of Industrial Engineering and Management, 8(1), 37-50. https://doi.org/10.3926/jiem.1298

Fonseca, L., \& Domingues, P. (2018). Exploratory research of ISO 14001:2015 transition among Portuguese organizations. Sustainability, 10(3), 781. https://doi.org/10.3390/su10030781 
Fonseca, L., Domingues, P., Baylina, P., \& Calderon, M. (2017). Management system certification benefits: Where do we stand? Journal of Industrial Engineering and Management, 10(3), 476-494. https://doi.org/10.3926/jiem.2350

Ghisellini, A., \& Thurston, D. L. (2005). Decision traps in ISO 14001 implementation process: Case study results from Illinois certified companies. Journal of Cleaner Production, 13(8), 763-777. https://doi.org/10.1016/j.jclepro.2004.02.042

Gomez, A., \& Rodriguez, M. A. (2011). The effect of ISO 14001 certification on toxic emissions: an analysis of industrial facilities in the north of Spain. Journal of Cleaner Production, 19(9), 1091-1095. https://doi.org/10.1016/j.jclepro.2011.01.012

Hasan, M., \& Chan, C. (2014). ISO 14000 and its perceived impact on corporate performance. Business and Management Horizons, 2, 1.

Hopkinson, P., James, P., \& Sammut, A. (2010). Environmental performance evaluation in the water industry of England and Wales. Journal of Environmental Planning and Management, 43(6), 873-895. https://doi.org/10.1080/09640560020001737

IBM. (2017). IBM SPSS Statistics for Windows (Version 25.0). IBM Corp., Armonk, NY. https://www.ibm.com/

Ingo, M., \& Klinkenberg, R. (2019). RapidMiner Studio 9.5.001 (Version rev:24d768). RapidMiner, Inc.

https://my.rapidminer.com/

International Organization for Standardization. (2013). Environmental management - environmental performance evaluation - guidelines (ISO 14031:2013). Geneva, Switzerland. https://www.iso.org/standard/52297.html

International Organization for Standardization. (2015). Environmental management systems - requirements with guidance for use (ISO 14001:2015). Geneva, Switzerland.

https://www.iso.org/standard/60857.html

King, A., Lenox, M., \& Terlaak, A. (2005). The strategic use of decentralized institutions: exploring certification with ISO 14001 management standard. Academy of Management Journal, 48(6). https://doi.org/10.5465/amj.2005.19573111

Kotu, V., \& Deshpande, B. (2015). Data exploration. In V. Kotu \& B. Deshpande (Eds.), Predictive analytics and data mining (pp. 37-61). Morgan Kaufmann.

https://doi.org/10.1016/B978-0-12-801460-8.00003-3

Link, S., \& Naveh, E. (2006). Standardization and discretion: Does the environmental standard ISO 14001 lead to performance benefits? IEEE Transactions on Engineering Management, 53(4), 508-519. https://doi.org/10.1109/TEM.2006.883704

Mansour, M. A. A., Khadar, S. D. A., \& Falqi, I. I. A. (2019). Analyzing the implementation of environmental laws in the Saudi Arabian construction industry. Applied Ecology and Environmental Research, 17(2), 3781-3802.

https://doi.org/10.15666/aeer/1702_37813802

Martín-Peña, M. L., Díaz-Garrido, E., \& Sánchez-López, J. M. (2014). Analysis of benefits and difficulties associated with firms' Environmental Management Systems: The case of the Spanish automotive industry. Journal of Cleaner Production, 70, 220-230. https://doi.org/10.1016/j.jclepro.2014.01.085

Mihailescu, N., Zahanagiu, A., \& Isbasoiu, R. (2011). Aspects of the implementation of ISO quality standards within INCDPM - ICIM Bucharest. Journal of Environmental Protection and Ecology, 12(3A), 1551-1562.

Murmura, F., Liberatore, L., Bravi, L., \& Casolani, N. (2018). Evaluation of Italian companies' perception about ISO 14001 and Eco Management and Audit Scheme III: Motivations, benefits and barriers. Journal of Cleaner Production, 174, 691-700. https://doi.org/10.1016/j.jclepro.2017.10.337
Nguyen, Q. A., \& Hens, L. (2015). Environmental performance of the cement industry in Vietnam: The influence of ISO 14001 certification. Journal of Cleaner Production, 96, 362378. https://doi.org/10.1016/j.jclepro.2013.09.032

Orlitzky, M., Siegel, D. S., \& Waldman, D. A. (2011). Strategic corporate social responsibility and environmental sustainability. Business \& Society, 50(1), 6-27.

https://doi.org/10.1177/0007650310394323

Poksinska, B. (2003). Implementing ISO 14000 in Sweden: Motives, benefits and comparisons with ISO 9000. International Journal of Quality \& Reliability Management, 20(5), 585-606. https://doi.org/10.1108/02656710310476543

Potoski, M., \& Prakash, A. (2013). Do voluntary programs reduce pollution? Examining ISO 14001's effectiveness across countries. Policy Studies Journal, 41(2), 273-294.

https://doi.org/10.1111/psj.12017

Prajogo, D., Ailie, K. Y. T., \& Lai, K.-H. (2014). The diffusion of environmental management system and its effect on environmental management practices. International Journal of Operations \& Production Management, 34(5), 565-585.

https://doi.org/10.1108/IJOPM-10-2012-0448

Prajogo, D., Tang, A. K. Y., \& Lai, K.-h. (2012). Do firms get what they want from ISO 14001 adoption?: an Australian perspective. Journal of Cleaner Production, 33, 117-126. https://doi.org/10.1016/j.jclepro.2012.04.019

Radonjič, G., \& Tominc, P. (2006). The impact and significance of ISO 14001 certification on the adoption of new technologies: The case of Slovenia. Management of Environmental Quality, 17(6), 707-727. https://doi.org/10.1108/14777830610702539

Ren, X. (2000). Development of environmental performance indicators for textile process and product. Journal of Cleaner Production, 8(6), 473-481. https://doi.org/10.1016/S0959-6526(00)00017-2

Schylander, E., \& Martinuzzi, A. (2007). ISO 14001 - experiences, effects and future challenges: a national study in Austria. Business Strategy and the Environment, 16(2), 133-147.

Sekaran, U., \& Bougie, R. (2013). Research methods for business: A skill-building approach (Vol. 34). Wiley.

Tam, C. M., Tam, V. W. Y., \& Zeng, S. X. (2002). Environmental Performance Evaluation (EPE) for construction. Building Research \& Information, 30(5), 349-361. https://doi.org/10.1080/09613210210150964

Tarí, J. J., Molina-Azorín, J. F., \& Heras, I. (2012). Benefits of the ISO 9001 and ISO 14001 standards: A literature review. Journal of Industrial Engineering and Management, 5(2), 297-322. https://doi.org/10.3926/jiem.488

Testa, F., Rizzi, F., Daddi, T., Gusmerotti, N. M., Frey, M., \& Iraldo, F. (2014). EMAS and ISO 14001: The differences in effectively improving environmental performance. Journal of Cleaner Production, 68, 165-173. https://doi.org/10.1016/j.jclepro.2013.12.061

Turk, A. M. (2009). ISO 14000 environmental management system in construction: An examination of its application in Turkey. Total Quality Management \& Business Excellence, 20(7), 713-733. https://doi.org/10.1080/14783360903036996

Wang, J.-X., \& Zhao, M.-Z. (2020). Economic impacts of ISO 14001 certification in China and the moderating role of firm size and age. Journal of Cleaner Production, 274, 123059. https://doi.org/10.1016/j.jclepro.2020.123059

Waxin, M.-F., Knuteson, S. L., \& Bartholomew, A. (2019). Outcomes and key factors of success for ISO 14001 certification: Evidence from an emerging Arab Gulf country. Sustainability, 12(1), 258. https://doi.org/10.3390/su12010258 
Zeng, S. X., Tam, C. M., Tam, V. W. Y., \& Deng, Z. M. (2005). Towards implementation of ISO 14001 environmental management systems in selected industries in China. Journal of Cleaner Production, 13(7), 645-656.

https://doi.org/10.1016/j.jclepro.2003.12.009

Zhang, W., Wang, W., \& Wang, S. (2014). Environmental performance evaluation of implementing EMS (ISO 14001) in the coating industry: Case study of a Shanghai coating firm. Journal of Cleaner Production, 64, 205-217. https://doi.org/10.1016/j.jclepro.2013.08.028

Zobel, T. (2013). ISO 14001 certification in manufacturing firms: a tool for those in need or an indication of greenness? Journal of Cleaner Production, 43, 37-44. https://doi.org/10.1016/j.jclepro.2012.12.014

Zobel, T. (2015). ISO 14001 adoption and industrial waste generation: The case of Swedish manufacturing firms. Waste Management \& Research, 33(2), 107-113.

https://doi.org/10.1177/0734242X14564643 